\title{
Diagnóstico diferencial em psicanálise: especificidades na prática clínica com um paciente depressivo
}

\section{Differential diagnosis in psychoanalysis: specificities in clinical practice with a depressed patient}

\author{
Amanda Lays Monteiro Inácio ${ }^{1}$
}

\begin{abstract}
Resumo
A depressão pode ser considerada como altamente prevalente na população mundial, adquirindo dessa forma uma crescente importância na prática analítica e assumindo a condição de predominância da motivação para a busca de tratamento. Objetiva-se no presente estudo oferecer um breve panorama da complexidade e vastidão do trabalho clínico com pacientes depressivos à luz da teoria psicanalítica e ressaltar a relevância do diagnóstico diferencial nesse contexto. Para tanto, serão utilizados fragmentos e discussões de um caso clínico atendido em uma clínica escola do curso de psicologia. Foram utilizados como aporte teórico conceitos psicanalíticos oriundos da teoria de Freud. Buscou-se enfatizar a relevância do diagnóstico diferencial em situações da prática clínica com pacientes depressivos, considerando as especificidades inerentes a esse tipo de caso, tais como a diminuição da autoestima e a ideação suicida. Palavras-chave: Depressão. Diagnóstico diferencial. Melancolia. Psicanálise. Psicoterapia.
\end{abstract}

\begin{abstract}
Depression can be considered highly prevalent in the world population, thus acquiring an increasing importance in analytical practice and assuming the predominance of motivation for searching treatment. The objective of this study is to provide a brief overview of the complexity and vastness of clinical work with depressive patients in the light of psychoanalytic theory and to highlight the relevance of differential diagnosis in this context. For that, we will use fragments and discussions of a clinical case attended in a clinical school of the psychology course. Psychoanalytical concepts derived from Freud theory and were used as a theoretical contribution. We sought to emphasize the relevance of differential diagnosis in situations of clinical practice with depressive patients, considering the specificities inherent to this type of case, such as the decrease of self-esteem and suicidal ideation
\end{abstract}

Keywords: Depression. Differential diagnosis. Melancholy. Psychoanalysis. Psychotherapy.

1 Psicóloga. Doutoranda do Programa Stricto Sensu em Psicologia da Universidade São Francisco. E-mail: amandalmonteiroo@ gmail.com 


\section{Introdução}

O presente artigo foi inspirado em questões derivadas do atendimento psicoterápico de orientação psicanalítica de um homem de meia idade acompanhado por aproximadamente um ano de psicoterapia (36 sessões) em uma clínica escola de Psicologia de uma universidade pública, no período de maio de 2015 a março de 2016. Nesse contexto, foram seguidos todos os procedimentos éticos respaldados na Resolução ${ }^{0} 510$, de 07 de Abril de 2016. O paciente, chamado neste estudo de S., já havia realizado psicoterapia no ano anterior aos atendimentos relatados, no mesmo local, com outra psicoterapeuta, apresentando desde o início a demanda de atendimento individual. Ressalta-se que a troca de psicoterapeuta deveu-se ao fato de tratar-se de uma clínica escola, onde todos os anos os alunos finalizam seus estágios e, por vezes, não dão continuidade aos atendimentos. No entanto, neste caso, todo o percurso clínico foi decorrente do aporte psicanalítico.

Ao longo das primeiras entrevistas, S. relatava insistentemente seu quadro depressivo e o quanto era acometido por angústia, tristeza e baixa estima, sendo que durante todo o processo psicoterapêutico o discurso permeou uma tendência ao suicídio, sendo observada uma menor frequência ao passar das sessões. No decorrer de seu caso, percebeuse uma vasta resistência ao trabalho analítico, o que se apresentava principalmente por meio de faltas corriqueiras e pedidos para finalizar a sessão antes dos 50 minutos. Em um dado momento da psicoterapia (cerca da décima sessão), decidiu-se pelo aumento da frequência de sessões de uma para duas vezes semanais, no entanto, o paciente não aderiu à solicitação e ocasionalmente desmarcava uma das vezes da semana ou permanecia por pouco tempo. A respeito da depressão, sua queixa advinha de um período bastante significativo, cerca de dez anos, em que S. buscou auxílio na psiquiatria e iniciou a medicação para o quadro depressivo. Ademais, somente nos últimos dois anos ele havia decidido iniciar a psicoterapia, após insistência de seus familiares e do próprio médico que viera o acompanhando.

Com base nesse panorama, estabelece-se a iniciativa de elucidar algumas questões referentes ao quadro da depressão e, na sequência, tecer considerações acerca do diagnóstico diferencial segundo a vertente da psicanálise inaugurada por Freud (1996b). Com essa premissa pretende-se oferecer um breve panorama da complexidade e vastidão do trabalho clínico com pacientes depressivos à luz da teoria psicanalítica e ressaltar a relevância do diagnóstico diferencial nesse contexto. A problemática em questão ganha sentido à medida que em seus diversos quadros clínicos, a depressão figura como uma das principais formas de manifestação do sofrimento psíquico presente na contemporaneidade, podendo ser considerada como altamente prevalente da população mundial e adquirindo dessa forma uma crescente importância na prática analítica, assumindo a condição de predominância da motivação para a busca de tratamento (DALGALARRONDO, 2008; PERES, 2010; TEIXEIRA, 2018).

\section{Vicissitudes da Depressão}

Desde os tempos mais remotos, a chamada "melancolia" é abordada em diferentes perspectivas teóricas que tentam elucidar suas especificidades no modo como acomete o sujeito. Com o passar do tempo ocorreu progressivamente a substituição do termo, sendo que no século XX, "melancolia" cedeu lugar ao termo científico "depressão" nos manuais e livros didáticos da psiquiatria (QUINTELLA, 2016). Atualmente, segundo o Manual Diagnóstico e Estatístico dos Transtornos Mentais - DSM-5 (APA, 2014), a depressão é reconhecida como Transtorno Depressivo Maior, oriunda do grupo de transtornos depressivos. A psicanálise, por sua vez, incumbese em seus primórdios do termo "melancolia" ao tecer considerações acerca do quadro clínico e seus possíveis determinantes, traçando as vicissitudes da subjetividade do sujeito pós-moderno que se 
apresentam por meio do sintoma frente às novas exigências da sociedade atual (GOMES; SILVA, 2018).

Segundo Peres (2010), a modificação na nomenclatura, apesar de fornecer especificidade aos termos, não evidencia a diminuição dos casos oriundos de quadros depressivos. Pelo contrário, ocorre em paralelo com uma verdadeira epidemia permeada por insegurança e desamparo do sujeito frente a uma sociedade com crises econômicas, desemprego, fragilidade das figuras parentais e de autoridade, violência, miséria, drogas, guerras e revoluções, enfim, abarcando uma infinidade de fatores fortemente depressores e que denunciam as contradições da nossa cultura. Em consonância, a psicanalista Kehl (2009) afirma que a depressão pode ser compreendida enquanto um sintoma social, visto que na contemporaneidade ela ocuparia um lugar de "mal estar na civilização" que desde a Idade Média fora ocupado pela melancolia. Em uma sociedade imediatista e extenuante, "os depressivos, além de se sentirem na contramão de seu tempo, veem sua solidão agravar-se em função do desprestígio social de sua tristeza" (KEHL, 2009, p. 21).

Destarte, Han (2017) problematiza a existência de uma relação direta entre os quadros de sofrimento na sociedade contemporânea com o modo de operar do capitalismo. Isso se traduz, para o autor, pelo excesso de positividade de nosso tempo, por meio do qual não haveria modo, tempo e lugar para se pensar a subjetividade humana, sobretudo o esgotamento típico dos sofrimentos psíquicos de nossa época. Em síntese, o autor revela que o imperativo do desempenho enquanto forma de operação da sociedade atual, que reverbera nas próprias relações sociais, conduz o sujeito à depressão.

No tocante aos termos "Luto" e "Melancolia", Freud (1996c) faz uma importante distinção em seu texto com o mesmo nome, assegurando que o luto trata-se de uma reação à perda de algo ou alguém, enquanto a melancolia afere a um quadro patológico orientado por características como a perda da capacidade de amar, quadros de inibição de diferentes tipos, redução considerável da autoestima, tendência a auto recriminações e expectativa delirante diante de punição. Segundo o autor, dentre essas particularidades, a diminuição da autoestima seria a única não encontrada nos pacientes em luto. Afora isso, as características seriam as mesmas.

Ainda quanto à diferenciação, no luto, o objeto amado realmente não existe mais, de modo que toda a libido é retirada de suas ligações com aquele objeto, não havendo nada de inconsciente a esse respeito. Assim, a elaboração no trabalho de luto demanda certo dispêndio de tempo e de energia psíquica. $\mathrm{Na}$ melancolia, por sua vez, a escolha inicial do objeto teria sido feita sobre uma base narcísica, escolha que é convertida em "identificação narcísica", sendo que o próprio ego do sujeito se torna pobre e vazio, de modo que a perda objetal é retirada da própria consciência do indivíduo (FREUD, 1996c).

Ao longo das sessões de S. importantes questões foram emergindo em seu discurso, possibilitando a instauração do trabalho analítico que, aos poucos, fora rompendo as barreiras de resistência. Desde as entrevistas iniciais sua fala instaurava-se no campo da perda de interesse pelo mundo externo e significativa diminuição da autoestima, com afirmativas quanto a se sentir um "velho gordo, feio e inútil" perante a sociedade, seus amigos e família. Essa questão possui grande relevância posto que o paciente encontrava-se desempregado há mais de dez anos, sendo que após a demissão de um importante cargo em uma empresa, nunca mais conseguiu se firmar em um emprego formal. Ele relata: (Sessão 2: Minha esposa fala que todo mundo gosta de mim, o problema é que eu não sei se eu gosto de mim, do meu jeito, do que eu estou passando"). A esse respeito, Freud (1996c), instaura que o melancólico considera que seu ego é indigno de estima e desprovido de valor. Assim, dirige a si mesmo sentimentos de culpa, tendo por vezes, delírios de inferioridade. 
Para além das questões relativas à inferioridade, S. tinha fortemente o desejo de ter sua antiga vida de volta, o que culminava em uma paralização em um dado momento da vida, um luto que ainda precisava ser elaborado (perda do trabalho, das amizades, do dinheiro, vida social, entre outras), causador de muito sofrimento e angústia. O paciente afirma: (Sessão 34: "Eu praticamente sustentava a casa, foi muito dificil, é muito difícil. Isso derruba a autoestima da gente. É ótimo você trabalhar pra caramba, mas depois poder comprar coisas, fazer churrasco, pagar curso do filho, essas coisas"). Neste ponto, ressalta-se que poucos estudos evidenciam que o luto é um processo natural de perda de qualquer elemento que represente um objeto de amor para o sujeito, processo este que pode ser beneficiado com o enfoque da psicanálise, haja vista sua forma de compreensão dos fenômenos nesse contexto (DALGALARRONDO, 2008; KUBLER-ROSS, 2017; SOARES; CASTRO, 2017).

Conforme exposto, uma das queixas principais do paciente era a perda de interesse no mundo externo após ficar desempregado. Quanto a isso, S. revela ser atualmente "a mulher da casa" o que o colocara em uma posição muito difícil posto que sempre foi o mantenedor de toda a família. Ele revela que seus dois filhos, já adultos, não comentam sobre o seu quadro depressivo e que sua única fonte de apoio seria a mulher, no entanto, este apoio já estaria de esgotando. S. afirma: (Sessão 12) "Quando sair daqui tenho um monte de coisas para fazer, vou pagar umas contas, dar uma passeada no shopping. Vou dar uma olhada nas vitrines e pagar contas, igual mulher". (Sessão 16) "Minha mulher trabalha e chega em casa todo dia eu estou com a mesma cara, ela fala: "Mas você toma tanto remédio como é que não melhora?". Eu acho que melhorou um pouco, mas é quase imperceptivel. A esse respeito, nota-se demasiada importância ao papel social desempenhado enquanto "homem da casa" e "pai de família", sendo a perda da própria masculinidade dentre desse contexto, um luto a ser vivenciado (FREUD, 1996c) e manejado ao longo da psicoterapia.
Ademais, o paciente suscita ao longo de todo o percurso analítico manifestações dessa violência por meio do discurso sobre ideação suicida, evidenciando pensamentos oriundos do passado, mas também no momento do tratamento. Tal quadro se revela em frases como: (Sessão 1) “Eu já pensei coisa bem pior. Mas hoje eu não penso mais em suicídio, já pensei, mas hoje não. Acho que a primeira forma de se aliviar seria o suicídio, mas eu não penso mais. Então na verdade o que eu faço quando estou em casa... eu tomo meu medicamento, deito e fico quietinho lá". (Sessão 8) "Se eu morrer hoje não seria problema nenhum, o meu medo é de ter alguma coisa fisica e ficar dando trabalho sabe, além do que já dou". (Sessão 13) "Mas hoje não tem nada disso, eu sinto uma angústia muito grande e dá vontade de sair correndo e me jogar na frente de um carro". (Sessão 16) "Às vezes a gente fica até pensando besteira porque do jeito que está eu penso que não dá para continuar, mas daí eu como cristão penso que não posso ser assim. É difícil porque às vezes você não está bem e precisa fingir que está para não magoar as pessoas". (Sessão 25) “Assim, acho que alguns nós estão tão amarrados que seria mais fácil cortar ele e emendar". A esse respeito, Freud (1996c, p. 257) revela:

"A análise da melancolia mostra agora que o ego só pode se matar se, devido ao retorno da catexia objetal, puder tratar a si mesmo como um objeto se for capaz de dirigir contra si mesmo a hostilidade relacionada a um objeto, e que representa a reação original do ego para com objetos do mundo externo".

Conforme fora dito, na melancolia, há uma identificação narcísica com o objeto, o que explicaria certa tendência ao suicídio. A ambivalência de sentimentos perante a vida e a morte seria, segundo Gomes e Gonçalves (2015), uma reação à perda que implica no empobrecimento subjetivo. Assim, ao se identificar, paradoxalmente, ao objeto perdido (o que é chamado de identificação narcísica), o sujeito entra em um movimento de assassinato de si mesmo, o que implica em uma autoflagelação subjetiva com o intuito de massacrar o próprio eu do melancólico. 
Vale ressaltar que Freud colocou a identificação na gênese do aparelho psíquico. Esforços foram feitos ao longo de diversos textos em sua obra em vias de desenvolver essa concepção. Apesar de não ser o foco do presente estudo aprofundar-se na temática do narcisismo, descreve-se, na sequência, uma breve explanação do desenvolvimento do tema a fim de uma melhor compreensão deste. Ao introduzir o conceito "narcisismo" em 1909, em uma reunião da Sociedade Psicanalítica de Viena, Freud o propõe como uma fase intermediária necessária entre o autoerotismo e o amor objetal. Contudo, anos mais tarde, o autor percebe ser necessário supor o que chamara de "uma nova ação psíquica" (FREUD, 1996g, p. 93), para que o narcisismo pudesse existir. A essa "nova ação" é dado o nome de identificação. Já em "Psicologia das massas e análise do eu" a importância do fenômeno de identificação é ampliada, sendo que próprio eu passa a ser entendido como se constituindo a partir de identificações (FREUD, 1996e).

Sobre a depressão decorrente do fracasso narcisista, Zimerman (2004) afirma que este associa-se a um estado depressivo decorrente de alguma frustração e, possível fracasso, que o sujeito sofre diante de suas demandas de obtenção de êxito, dinheiro e prestígio. Tal elucidação vai ao encontro do quadro clínico de S., posto que seu estado depressivo iniciou-se com a perda do emprego, do qual o próprio paciente revela furtivamente ter ocupado um cargo de confiança e poder. Desta feita, ao longo das sessões, o caminho trilhado entre paciente-psicoterapeuta tinha por finalidade a diminuição das dispendiosas grandezas de uma vida que já não o pertencia mais, fazendo com que $\mathrm{S}$. buscasse em seu momento atual de vida novas motivações para viver e, principalmente, lidar com as questões que o mantinham paralisado no passado.

Ao longo do processo psicoterápico, foi possível perceber ainda uma maior abertura aos próprios sentimentos, fantasias e emoções. Nas primeiras sessões, S. demonstrava se importar demasiadamente com a opinião da esposa e com o apoio por ela prestado. Ele afirma: (Sessão 4) "Eu sei que o que eu estou passando é muito complicado, me sinto inútil, minha esposa diz que eu ajudo muito na familia, mas se fosse outra já tinha desistido de mim". (Sessão 6) "Sim, é muito diferente quando eu estou melhor de quando tenho as recaídas, minha sorte é que tenho um anjo na minha vida, que é a minha esposa". Por volta da vigésima sessão, começa a trazer indícios de que o casamento passa por momentos difíceis, afirmando que o casal dorme em quartos separados por conta de $\mathrm{S}$. acordar várias vezes à noite e que a vida sexual anda "fraquinha". Ademais, o paciente revela seu descontentamento com a falta de expressão de afeto da esposa, dando indícios de que ele mesmo possui pouco interesse sexual nela, o que pode ser atrelado aos medicamentos que toma, segundo o próprio.

Foi observado ao longo das sessões que o paciente passou a falar mais a respeito de si mesmo, suas dificuldades em se comunicar com os familiares, sobretudo a esposa, a vergonha por estar desempregado, suas questões relacionadas à autoestima e, ainda, o desejo de ter sua vida antiga de volta. Questões essas que demandam um enfrentamento da realidade e principalmente uma abertura para as emoções (ZIMERMAN, 2004), o que pouco a pouco foi apontado pela psicoterapeuta e trabalhado nas sessões, trazendo assim avanços que podem ser notados no seguinte discurso: (Sessão 34) "Sim, antes eu tinha essa ideia sabe, de querer minha vida de volta, querer que tudo voltasse num passe de mágica a ser como antes. Hoje eu vejo que se tivesse oportunidade de voltar para aquele emprego, não voltaria. Eu não daria conta de tanto funcionário, assalto todo dia, acordar de madrugada, eu não quero o emprego de antes de volta, queria apenas voltar a ser aquela pessoa".

Segundo Gomes e Silva (2018) o sofrimento psíquico que predomina na contemporaneidade manifesta-se sob a forma da depressão, atingindo sintomaticamente o sujeito que não tem tempo para nada e aquele que possui tempo exacerbado de tédio. 
É nesse contexto segundo dos autores que surgem os sentimentos de tristeza e apatia, que tem como pano de fundo a busca de uma identidade. Segundo Moraes e Loffredo (2019), aspectos como a aceleração e demandas exaustivas propostas pelos novos modos de regulação temporal, sobretudo no trabalho, não se harmonizam com o tempo do sujeito, imprimindo o desencadeamento desse sofrimento. Para as autoras, a volatilidade do mundo atual somada às características até então mencionadas enquanto presentes nesse contexto podem ser articulados a uma condição traumática, se nos reportarmos a definição freudiana de "trauma", segundo a qual refere-se a uma vivência que traz para a vida psíquica estímulos dos quais a resolução ou elaboração não ocorrem de forma costumeira, gerando perturbações no funcionamento da energia (FREUD, 2014).

Nesse sentido, pode-se inferir que a ênfase da psicoterapia foi a promoção de uma gradual e muito difícil renúncia às ilusórias e grandiosas aspirações e também auxiliar o paciente a entrar em contato com suas emoções por meio de uma melhor capacidade de simbolização (MORAES; LOFFREDO, 2019; ZIMERMAN, 2004). Buscouse ainda promover uma melhora em sua autoestima por meio da mudança na forma de compreender a situação presente na qual se encontra além de obter maior abertura para o momento atual de sua vida. Sobre esses fatos, observou-se também uma maior valorização do processo psicoterapêutico e diminuição das resistências, conforme afirma já em uma das últimas sessões: (Sessão 36) "Quando eu venho aqui consigo explicar o que está acontecendo, desabafar sabe, não consigo falar dessas coisas que falo aqui com a minha esposa, ou com um amigo, ou uma amiga, coisa que não existe. Acho que quando você está com problemas tem que procurar alguém que possa realmente te ajudar e por isso venho aqui".

Com base nos pressupostos elucidados da teoria freudiana e nos fragmentos do caso clínico apresentado, concluiu-se que o paciente apresentava traços melancólicos em uma estrutura clínica de uma neurose histérica. A esse respeito, serão tecidas, na sequência, considerações acerca do diagnóstico diferencial em psicanálise.

\section{Diagnóstico Diferencial à Luz da Psicanálise}

A cientificidade da Psicanálise vem sendo abordada sob diferentes vertentes ao longo de toda sua existência. A crítica mais comum, de acordo com Mezan (2007) diz respeito à suposta pouca eficácia do tratamento analítico quando comparado a outras modalidades de terapias e/ou à ação medicamentosa. $\mathrm{O}$ autor cita ainda a concepção na qual a problemática é levantada em virtude do rigor da teoria psicanalítica, tratando-a como baseada em métodos impossíveis de serem verificados. Há ainda aqueles que juntam ambos os pressupostos, afirmando que a falta de teor científico e eficácia terapêutica impelem sua não cientificidade.

Há diversos momentos ao longo da obra freudiana em que o autor postula qual seria a natureza da Psicanálise. A argumentação mais completa encontra-se na última das "Novas conferências de introdução à psicanálise" de Freud (1996a), cujo título é "Sobre uma Weltanschauung". Por tratar-se de um texto escrito em sua velhice, pressupõe-se que este representa sua opinião definitiva sobre $o$ assunto (MEZAN, 2007). Weltanschauung significa visão de mundo, sendo que a palavra mundo referese à vida psíquica do homem, tanto individual quanto em sociedade. $\mathrm{O}$ termo em questão oferece critérios claros tanto para compreender o que nos rodeia, quanto para definir modos de conduta convergentes com os pressupostos da técnica psicanalítica em si. Dá análise do autor, como destaca Palmeira e Gewehr (2015), pode-se conceber que a Psicanálise não necessita de uma Weltanschauung própria, pois adota a concepção de mundo científica. Incluise a mente humana como objeto de estudo e sua contribuição consiste em estender-se aos conteúdos do psiquismo, até então desconsiderados.

Nessa perspectiva, cabe evidenciar que a Psicanálise se apresenta na contramão de uma 
vertente curativa, tal qual outras concepções se direcionam, dentre elas a psiquiátrica. Ela não tem como pressuposto a eliminação do sintoma, mas a recuperação da autonomia do paciente, ou seja, sua capacidade de agir perante os acontecimentos da vida. Escrevendo a Ferenczi, Freud afirma: "Não se deve lutar por eliminar os complexos, mas por colocar-se de acordo com eles: os complexos são, legitimamente, aquilo que dirige a conduta de um homem no mundo" (FREUD; FERENCZI, 1992, carta de 17 nov. 1911). Assim, o que se busca são condições psíquicas mais condizentes com a realidade do sujeito, o que demanda um trabalho árduo com especificidades inerentes a um diagnóstico diferencial.

Em "Sobre o início do tratamento" Freud (1996f, p. 140), recomenda aos analistas que façam uma experiência preliminar no princípio de uma análise, empreendida como uma "sondagem" por uma ou duas semanas, para que então se estabeleça o diagnóstico diferencial. Ele afirma que é de extrema utilidade que o analista assim proceda, como forma de evitar erros práticos que desacreditem seu método de tratamento. Ademais, no que tange aos critérios diagnósticos, o que se extrai de seus relatos clínicos é que havia uma atenção direcionada aos sintomas típicos (paralisias histéricas, rituais obsessivos, entre outros), mas, sobretudo, uma análise convocada pelo modo como cada sujeito se posicionava diante de seu sintoma, o que acaba por direcionar de maneira decisiva a orientação do tratamento (LIMA et al., 2015; MOREIRA; TEIXEIRA, 2018).

A depressão, ou as depressões, ficaram por muito tempo em evidência sob a ótica da psiquiatria, sem que a psicanálise comungasse desse campo exclusivamente (GOMES; SILVA, 2018; QUINTELLA, 2016). Assim como a criação da psicanálise deu-se em virtude das manifestações histéricas, trazendo um método próprio de tratamento da doença mental, hoje, é a depressão que desafia, por meio dos diagnósticos clínicos, etiologias e tratamentos, na concepção do que seriam as doenças mentais. Sob essa circunstância, o modelo biológico predominou e ainda predomina, por vezes, na explicação das causas do sofrimento psíquico, tratados sobremaneira por meio da medicalização, o que segundo Kehl (2009) não deve desencorajar o pensar psicanalítico sobre esses fenômenos.

Roudinesco (2000) afirma que o conflito neurótico contemporâneo é posto como se não houvesse relação com nenhuma causalidade psíquica oriunda do inconsciente. Entretanto, esse inconsciente se mostra presente através do corpo, operando uma forte resistência às práticas que visam repeli-lo. $\mathrm{Na}$ psicanálise, trata-se de um desamparo fundamental, uma problemática relacionada à perda, a falta e ao vazio estrutural do sujeito, enquanto a psiquiatria oferece vias de uma explicação por insuficiência biológica, sendo o déficit neuro-hormonal a explicação plausível aos quadros depressivos (PERES, 2010).

O caráter histórico da concepção biológica de tratamento das doenças mentais não se apresenta como foco do presente estudo. Contudo, tem-se que essa historicidade possui relevância à medida que traz explicações condizentes com o que se pretende elucidar. Segundo Peres (2010) é possível pensar o desenvolvimento da temática segundo duas concepções. A primeira, elucidada pelo pai da psicanálise evidencia o caráter estruturante da depressão, inaugurando o caminho para as intervenções psicanalíticas e psicoterapêuticas. Já a segunda concepção refere-se Pierre Janet, que alude a uma noção de insuficiência inata do indivíduo enquanto possuidor de um déficit orgânico e biológico. O esforço diagnóstico e terapêutico acaba por estabelecer dois grandes grupos, um liderado pelos psicanalistas e psiquiatras de orientação psicanalítica, e outro agrupando os psiquiatras que, seguindo uma tradição kraepeliana, enfatizam com menor vigor as causas etiológicas e mais a sintomatologia, por meio de modelos padronizados, descrições de síndromes e enumeração de sintomas (DUNKER, 2014). 
A esse respeito, Kehl (2009) evidencia que a demissão ante o desejo que acomete o neurótico conduz os pacientes depressivos, em sua maioria, a busca pela medicalização. Apoiados por uma ideologia científico-mercadológica que apoia a oferta abundante de antidepressivos, muitos se sujeitam ao tratamento exclusivamente psiquiátrico, o que se mostra uma condição ideal ao não enfretamento das questões subjetivas. Tal evidência vai ao encontro da concepção levantada por Roudinesco (2000), sobre a dificuldade enfrentada pelo indivíduo na contemporaneidade para lidar com sua própria subjetividade.

Diante do exposto, evidencia-se a questão levantada por Lima et al. (2015) sobre quais seriam os indícios clínicos estruturais para o diagnóstico da neurose histérica (conforme abordado no caso de S.) em uma época que define o diagnóstico e a direção de tratamento das psicopatologias tendo por base, principalmente, a referência a uma totalidade orgânica do campo biológico. Os autores afirmam que o foco da psiquiatria na homogeneidade do transtorno como solução à pluralização das formas clínicas conduziu à supressão da dimensão subjetiva própria à neurose. Tal fato fica em evidência no caso apresentado ao recordarmos o que fora exposto anteriormente, acerca do tempo passado entre o início da sintomatologia (na qual o paciente foi em busca do tratamento psiquiátrico) e, que somente oito anos depois, nos últimos dois anos, S. procurou a psicoterapia de base psicanalítica após insistência de seus familiares e do próprio médico que o atendia.

Em seu estudo, Dunker (2014) faz uma crítica à racionalidade diagnóstica pautada em um modelo fortemente biologizante, que torna formas de sintoma e de mal-estar parte de um processo social de alienação e de mercantilização do sofrimento. Segundo o autor, o sistema diagnóstico desenvolvido pela Associação Psiquiátrica Americana (APA) em suas mais diversas modalidades, sendo a mais recente o DSM-5 (APA, 2014), tornou-se um objeto importante, na medida que fixa e estabelece uma maneira de pensar e talvez induza um tipo de psicopatologia que não é necessário nem deveria ser pensado como hegemônico em termos de pesquisa, de financiamento em saúde mental ou de justificação clínica. Essa problemática associa-se diretamente ao campo de interesse da psicologia e da psicanálise, posto que o diagnóstico conduzido nessas diferentes instâncias orienta o manejo clínico, atuação profissional e medicação utilizada, impactando de modo infindável na vida do sujeito.

Dalgalarrondo (2008) afirma que os valores e limites do diagnóstico psiquiátrico são debatidos a exaustão, contudo, não há consenso sobre uma posição de sua eficácia e utilização. A esse respeito, o autor destaca a existência de duas correntes, uma que se orienta pelo pressuposto de que o diagnóstico feito pela psiquiatria não possui valor algum, posto que cada sujeito e realidade é única e inclassificável. O segundo pressuposto vai em defesa do diagnóstico psiquiátrico, sustentando-o como o elemento principal e mais efetivo na prática psiquiátrica. Segundo o autor, há uma relação dialética permanente entre o particular, individual e o que é universal, sendo todos esses fundamentos imprescindíveis para uma classificação.

Desta feita, Dunker (2014) assegura que a psiquiatria e parte da medicina conservadora brasileira, precisam considerar que a definição dos quadros psicopatológicos, a reintrodução criteriosa de noções como mal-estar e sofrimento, o diálogo científico com outras matrizes políticas e epistemológicas são medidas necessárias para um programa de atenção e tratamento que leve em conta a complexidade do sujeito e de um campo transversal como a saúde mental. Aliado a isso, Zimerman (2004) aventa para as vertiginosas e profundas transformações que o mundo globalizado vem sofrendo, mudanças estas que ao mesmo tempo aproximam e distanciam o sujeito do seu próprio eu e de suas relações, perfazendo uma sociedade marcada por contradições e principalmente pela dificuldade em acessar as próprias emoções. 
Assim, retomamos o pressuposto de Han (2017), ao mencionar a positividade exacerbada, dentre outros fatores, que acometem nossa sociedade, sobretudo no tocante aos quadros depressivos.

Em seu texto magistral "O mal estar na civilização", Freud (1996d) afirma que a felicidade deve ser vivenciada como um fenômeno episódico, enquanto a infelicidade é facilmente experimentada, pois padecemos de diversas fontes de sofrimento ao longo da vida. A esse respeito, Peres (2010, p. 21) afirma:

Freud se detém particularmente na "fonte social do sofrimento" e nos chama a atenção para a situação paradoxal de o próprio homem ser responsável por criar situações que se revertem em maior fonte de mal-estar. Para ele, uma análise histórica acurada poderia nos levar a determinados acontecimentos que teriam contribuído para produzir essa atitude de hostilidade para com a civilização. Afastado da natureza, o indivíduo é submetido a uma série de frustrações, na procura de atingir um ideal culturalmente estabelecido, e é dessa situação que vai surgir a sua neurose. $\mathrm{O}$ grande progresso efetuado pela ciência e sua aplicação técnica, altamente elogiáveis, não tornam o homem mais feliz. Ele pode sentir-se onipotente, qual um "Deus de Prótese" com todos os apetrechos que criou, porém verdadeiramente nada faz parte dele.

Segundo Freud (1996d) o processo de civilização fez com que o homem desenvolvesse o sentimento de culpa, ao passo que o preço pago pelo advento desses avanços seria a perda da felicidade e um ganho de culpabilidade, culpa essa que permeia constantemente o melancólico. A sociedade atual preza preponderantemente pela beleza, consumo, prestígio e poder, ficando a cargo do sujeito mascarar sua infelicidade e solidão para pertencer ao contexto que se apresenta e demanda incessantemente (TEIXEIRA, 2018; ZIMERMAN, 2004). Segundo Quintella (2016), a clínica psicanalítica na contemporaneidade lida cada vez mais com as depressões oriundas de um ideal que é característico da atualidade, onde a busca pelo imediatismo da satisfação pulsional e a tentativa de supressão da temporalidade são marcas que prevalecem na subjetivação.

Em consonância, Peres (2010) destaca que nossa civilização atua de tal modo que favorece o desenvolvimento dos quadros depressivos. No caso de S. conforme fora exposto, suas idealizações e o desejo de ter a antiga vida de volta estavam diretamente ligadas ao prestígio e poder social, econômico e familiar que o emprego the oportunizava. Diante de uma falta (o desemprego e as sucessivas perdas decorrentes dele), a dificuldade em entrar em contato com as próprias emoções, que pouco foram resolvidas em oito anos de tratamento exclusivamente medicamentoso, fora aos poucos (ao longo de 2 anos) sendo oportunizada pelo processo psicoterápico.

Ressalta-se que a premissa da medicalização e do reducionismo biológico não é tratada de forma indiferente ou negativa no presente estudo. Contudo, em consonância com as proposições de Roudinesco (2000), Kehl (2009) e Dunker (2014), a problemática em si precisa urgentemente ser colocada em pauta e aprofundada, posto que sua eficácia pode ser beneficiada por meio do contato com questões de ordem emocional e inconsciente emergidas em um processo psicoterapêutico de orientação psicanalítica.

\section{Considerações Finais}

O presente estudo se propôs a oferecer um breve panorama da complexidade e vastidão do trabalho clínico com pacientes depressivos à luz da teoria psicanalítica e ressaltar a relevância do diagnóstico diferencial nesse contexto. $\mathrm{O}$ caso clínico apresentado proporciona tal panorama e sua problematização junto ao diagnóstico diferencial em psicanálise configuram pressupostos de fundamental importância para aqueles profissionais que trabalham com o psiquismo humano. Ademais, são 
trazidas breves considerações acerca da depressão enquanto sintoma social da contemporaneidade e a diferenciação quanto reducionismo biológico no manejo do diagnóstico em psiquiatria diante das vicissitudes abordadas pela psicanálise. Desse modo, espera-se que o estudo venha a contribuir aos estudiosos da temática, sobretudo aos que trabalham com pacientes depressivos, oportunizando novas e instigantes problematizações.

\section{Referências}

APA - AMERICAN PSYCHIATRY ASSOCIATION. Manual diagnóstico e estatístico de transtornos mentais: DSM-5. 5. ed. Porto Alegre: Artmed, 2014.

DALGALARRONDO, P. Psicopatologia e semiologia dos transtornos mentais. Porto Alegre: Artmed, 2008.

DUNKER, C. I. L. Questões entre a psicanálise e o DSM. Jornal de Psicanálise, São Paulo, v. 47, n. 87, p. 79-107, 2014. Disponível em: http://pepsic. bvsalud.org/scielo.php?script=sci_arttext\&pid=S0103$58352014000200006 \& \operatorname{lng}=$ pt\&tlng=pt. Acesso em: 20 mar. 2019.

FREUD, S. $18^{\text {a }}$ Conferência: a fixação no trauma, o inconsciente. In: FREUD, S. Obras completas. São Paulo: Companhia das Letras, 2014. v. 13, p. 297-310.

FREUD, S. A questão de uma Weltanschauung. In: FREUD, S. Edição brasileira das obras completas de Sigmund Freud. Rio de Janeiro: Imago, 1996a. v. 22, p. 155-177.

FREUD, S. Dois verbetes de enciclopédia. In: FREUD, S. Edição brasileira das obras completas de Sigmund Freud. Rio de Janeiro: Imago, 1996b. v. 18, p. 245-265.

FREUD, S. Luto e melancolia. In: FREUD, S. Edição brasileira das obras completas de Sigmund Freud. Rio de Janeiro: Imago, 1996c. v. 14, p. 245-265.

FREUD, S. O mal-estar na civilização. In: FREUD, S. Edição brasileira das obras completas de Sigmund Freud. Rio de Janeiro: Imago, 1996d. v. 21, p. 67-73.

FREUD, S. Psicologia de grupo e a análise do ego. In: FREUD, S. Edição brasileira das obras completas de Sigmund Freud. Rio de Janeiro: Imago, 1996e. v. 18, p. 91-179.

FREUD, S. Sobre o início do tratamento (Novas recomendações sobre a técnica da psicanálise I). In: FREUD, S. Edição brasileira das obras completas de
Sigmund Freud. Rio de Janeiro: Imago, 1996f. v. 12, p. 137-139.

FREUD, S. Sobre o narcisismo uma introdução. In: FREUD, S. Edição brasileira das obras completas de Sigmund Freud. Rio de Janeiro: Imago, 1996g. v. 14, p. 77-108.

FREUD, S.; FERENCZI, S. Correspondance 1908-1914. Paris: Calmann-Lévy, 1992.

GOMES, L. B.; GONÇALVES, J. R. Processo de luto: a importância do diagnóstico diferencial na prática clínica. Revista de Ciências HUMANAS, Florianópolis, v. 49, n. 2, p. 118-139, 2015. Disponível em: https://periodicos. ufsc.br/index.php/revistacfh/article/viewFile/21784582.2015v49n2p118/30842. Acesso em: 20 mar. 2019.

GOMES, L. Q.; SILVA, G. S. A depressão: da história para a clínica psicanalítica contemporânea. Revista Ciência (In)Cena, Salvador, v. 1, n. 6, p. 51-68, 2018. Disponível em: http://revistaadmmade.estacio.br/index. $\mathrm{php} /$ cienciaincenabahia/article/viewFile/4517/pdf4517. Acesso em: 21 mar. 2019.

HAN, B. Sociedade do cansaço. 2. ed. Petrópolis: Vozes, 2017.

KEHL, M. R. O tempo e o cão: a atualidade das depressões. São Paulo: Boitempo, 2009.

KUBLER-ROSS, E. Sobre a morte e o morrer. São Paulo: Martins Fontes, 2017.

LIMA, C. H.; VALIANTE, L. S.; FERNANDES, F. B.; LOPES, A. F. P. Clínica psicanalítica da neurose histérica na contemporaneidade. Estudos Contemporâneos da Subjetividade, Rio de Janeiro, v. 5, n. 1, p. 93-107, 2015. Disponível em: http://www.periodicoshumanas.uff.br/ ecos/article/view/1409. Acesso em: 21 mar. 2019.

MEZAN, R. Que tipo de ciência é, afinal, a Psicanálise? Natureza Humana, São Paulo, v. 9, n. 2, p. 319-359, 2007. Disponível em: http://pepsic.bvsalud.org/pdf/nh/ v9n2/v9n2a05.pdf. Acesso em: 24 set. 2019.

MORAES, D. F. L.; LOFFREDO, A. M. Tempo e trabalho na contemporaneidade: notas para uma agenda de pesquisa no campo da psicanálise. Cadernos de Psicanálise, Rio de Janeiro, v. 41, n. 40, p. 65-82, 2019. Disponível em: http://cprj.com.br/ojs_cprj/index.php/ cprj/article/view/140. Acesso em: 24 ago. 2019.

MOREIRA, I. G.; TEIXEIRA, A. M. R. Diagnóstico em psicanálise: da estrutura ao discurso. Revista Latinoamericana de Psicopatologia Fundamental, São Paulo, v. 21, n. 4, p. 739-760, 2018. Disponível em: $\quad \mathrm{http}: / / \mathrm{www}$. scielo.br/scielo.php?script=sci abstract\&pid=S1415-47142018000400739\&lng=pt\&nr m=iso. Acesso em: 15 fev. 2019. 
PALMEIRA, A. B. P.; GEWEHR, R. B. Existe uma Weltanschauung da Psicanálise? Cadernos de Psicanálise, Rio de Janeiro, v. 37, n. 32, p. 63-84, 2015. Disponível em: http:/cprj.com.br/imagenscadernos/ caderno32_pdf/04_Existe-uma-Weltanschauung-daPsicanalise.pdf. Acesso em: 24 ago. 2019.

PERES, U. T. Depressão e melancolia. Rio de Janeiro: Zahar, 2010.

QUINTELLA, R. R. Depressão contemporânea e metapsicologia freudiana: pensando a neurose na atualidade. Reverso, Belo Horizonte, v. 38, n. 71, p. 65-73, 2016. Disponível em: http://pepsic.bvsalud. org/scielo.php? script $=$ sci_arttext\&pid $=$ S $0102-$ 73952016000100007\&lng=pt\&nrm=iso. Acesso em: 28 mar. 2019.

ROUDINESCO, E. Porque a psicanálise? Rio de Janeiro: Zahar, 2000.
SOARES, L. G. A.; CASTRO, M. M. Luto: colaboração da psicanálise na elaboração da perda. Psicologia $e$ Saúde em Debate, Patos de Minas, MG, v. 2, n. 3, p. 103-114, 2017. Disponível em: https:/www.psicodebate. dpgpsifpm.com.br/index.php/periodico/article/view/167. Acesso em: 20 mar. 2019.

TEIXEIRA, M. A. R. Melancolia e depressão: um resgate histórico e conceitual na psicanálise e na psiquiatria. Revista de Psicologia da UNESP, São Paulo, v. 4, n. 1, p. 41-56, 2018. Disponível em: http://seer.assis.unesp. br/index.php/psicologia/article/view/997. Acesso em: 29 mar. 2019.

ZIMERMAN, D. E. Manual de técnica psicanalítica: uma re-visão. Porto Alegre: Artmed, 2004. 
